\title{
Modeling Break-even Zone Using the Integral Methods
}

\author{
Liliana Horal \\ Department of Finance \\ Ivano-Frankivsk National Technical \\ University of Oil and Gas \\ Ivano-Frankivsk, Ukraine \\ http://orcid.org/0000-0001-6066-5619
}

\author{
Vira Shyiko \\ Department of Finance \\ Ivano-Frankivsk National Technical \\ University of Oil and Gas \\ Ivano-Frankivsk, Ukraine \\ https://orcid.org/0000-0002-2822-0641
}

\author{
Oleh Yaroshenko \\ VRTP "Ukrgasenergoservis" \\ PJSC "Ukrtransgas" \\ Kyiv, Ukraine \\ lilianag@ua.fm
}

\begin{abstract}
Researched the break-even activity processes of enterprises. Results showed that for certain types of activities there is no single traditional break-even point, there is a whole range of production volumes, which has the principles of break-even activity. Taking into account these aspects, it is proposed to improve the method of calculation of break-even points. Based on the application of averages theory and deviations analysis, calculated the minimum and maximum break-even point. These calculations allowed to simulate the equation of integration's lines. Determined the area of the zone of general activity, the break-even zone, the zone of losses, the zone of profits and the zone of financial security using the properties of a certain integral. To assess the efficiency of enterprises, proposed to determine the share of each of the zones in the total area of the enterprise's activity. The value of the calculated shares will allow to identify the bottlenecks of the enterprises's activity and determine the ways of increasing the efficiency of the activity, to optimize the activity.
\end{abstract}

Keywords: break-even zone, costs, revenues, volume, financial security

\section{INTRODUCTION}

With the development of modern methods of modeling various aspects of business entities, the problem of determining the effective direction of enterprise development arises. An indispensable element of ensuring the effective operation of enterprises is to determine the level of breakeven activity, which is for an enterprise that begins its activity a benchmark and criterion, which makes it possible to determine whether it is advisable to carry out this activity in the light of existing competition in the market, while for an enterprise that already operating, the break-even point is an element of performance monitoring. A well-known method for determining the break-even point is Cost-ValueProfit-analysis (CVP-analysis), the features and principles of which have been studied in detail by many domestic and foreign scientists. However, based on the research [1, 2], it can be determined that for some activities, such as underground storage of natural gas [2], there is not a single point of unbroken volume, and there is a whole break-even interval of activity. Therefore, in accordance with the findings of existing studies $[1,2]$, it is necessary to propose a method for determining area of break-even activity of enterprises, which are characterized by break-even intervals and to offer an analysis of their activity effectiveness.

\section{LITERATURE REVIEW}

The study of theoretical foundations and methodological provisions of the break-even point determination and the analysis of break-even production activities were carried out by domestic and foreign scientists. Among the domestic researchers who formed the theoretical basis for the study of break-even activity of business entities can be distinguished Masyuk Y.V. [3], Skurtol S.D. [4], Babenko M.V. [5], Yankovyi O.G. [ 6], Yushchenko N. L. [7], Vetzepura N. [8], Tkachenko S.M. [9], Tarasenko O. M. [10]. Let's take a closer look at their developments. In particular, Masyuk Y.V. [3] proposes, along with the basic characteristics of breakeven, to calculate the break-even rate as the ratio of constant costs to the product of marginal profit and production capacity. According to him, this indicator will determine what factors affect the break-even volume of production and will give an opportunity to really assess its risk. In his research [4], Skurtol S.D. proposed to simulate the breakeven point with the use of information systems. In the given work the procedure for determining the break-even point for a multi-unit production company is demonstrated. Babenko M.V. considers the procedure for determining the value of software development in the analysis of break-even, as well as in work [5] proposed a software tool for automation of the break-even analysis process for the creation of information systems, with the help of which it is possible to provide a life cycle planning development software product. Yankovyi O.G., in his research [6], proved that all generalizing CVP analysis at the enterprise level has the full right to exist and be used, especially since none of them contradicts the classical theory of break-even at the level of a particular product. The correctness of their analytical application at the enterprise level, above all, lies in the plane of a wellgrounded transition to a higher level of generalization. The fulfillment of this precondition is ensured by the fact that these indicators (especially relative ones) should be based strictly on the basic provisions of statistical science, in particular, the theory of averages. Yushchenko N. L. and Kusliy I.P. in their work [7] classified and made a comparison of the functional capabilities of software products available in the market of Ukraine, implementing the break-even analysis models, which is an important element of the analysis of the relationship "cost-volumeprofit" Vetsepura N. [8] investigated the features of the break-even economic model use, accounting and mathematical approach to the analysis of break-even, as a result of the research it was determined that the economic model is more realistic, since it is assumed that the curve of aggregate expenditures is nonlinear, and more flexible method of obtaining proper information, rather than a graphic method (and more appropriate for data entry in a computer financial model), is a mathematical approach. 
Tkachenko S.M. [9], using the systematic approach of the relationship between break-even production, commercial activity and economic sustainability of an agricultural enterprise, determined the impact of production and commercial activity on the level of economic stability of the enterprise. On the basis of the concept of break-even, strategies for ensuring economic sustainability of the agrarian enterprise were developed and specific directions of their implementation for the spheres of activity of the enterprise were identified. O.M. Tarasenko [10] proposed in his work to define two break-even points, as in previous papers [11] it was proved that the volumes of passenger transportation on the bus route with enough for practical use are accurately described by the law of parabolas of the second order.

Such domestic scientists as: Goral L.T. [1] Yaroshenko A.L. [2], Prilepova M.O. [12], Yushchenko N.L. [13], Chimshit S.I. [14], were engaged in formation of theoretical and applied principles and methodological aspects of defining the break-even zone. Prylepova M.O. supporting the ideas of Chimshit S.I. and Grabovsky I.S. [14] proposed the basic strategies of the company's behavior based on the concept of a break-even zone in accordance with four basic management tools: the weighted average price of the company's products; sales volumes in physical units; total fixed costs; unit cost of production. In her work, the author states that each of the strategies has certain problem aspects in the enterprise and the disadvantages. At the heart of the financial and economic mechanism of enterprise management, on the principles of the break-even zone concept, there are two key criteria: the reduction of the break-even threshold; reducing the area of the figure, which means increasing the stability of the system. The matrix of break-even zone change and profitability thresholds was developed [12]. It is proposed to divide the break-even zone into four sectors, each of which has its own specific operating conditions and further development of the enterprise. The basic methodical recommendations for enterprise management in different segments of the breakeven zone are determined.

Among the foreign scientists who were engaged in the study of theoretical, methodological and practical aspects of break-even activity, one can distinguish: Dr. Murari Premnath Sharma [15], Minhyun LEE, Taehoon HONG, Choongwan KOO, Chan-Joong KIM [16], M. B. Ndaliman, U. Y. Suleiman [17], Rudolf Kampf, Peter Majerčak, Pavel Švagr [18], P. Aswal, M. Kumar, A. Gupta [19], Adriana Mihaela IONESCU, Cristina Elena DUMITRU [20], Nemanja Stanisic, Goranka Knezevic [21], Dr. Nabil Alnasser, Dr. Osama Samih Shaban, Dr. Ziad Al-Zubi [22].

In his research [15] Dr. Murari Premnath Sharma indicates, that: "we always calculate Break Even Point of the Product only and never think about services sector like banking institution". Her research paper developed the formula and methodology for banking break-even point. Which indicates that amount of lending and deposit will recover the fixed cost and if there is desired profit it will also calculate. Minhyun LEE, Taehoon HONG, Choongwan KOO, Chan-Joong KIM conducted the study that demonstrated an economic assessment of the residential solar PV systems in the 50 states and the District of Columbia by considering the existing state solar incentives in the U.S.
Towards this end, the study conducted a break-even analysis using $\mathrm{LCC}$ and $\mathrm{LCCO}_{2}$ analyses and converted the economic and environmental values into NPV, PI and PP. Furthermore, to analyze the impact of the state solar incentives on the economic feasibility of the residential solar PV systems in each state, the study examined the PI increase ratio of scenario 1 (without state solar incentives) and scenario 2 (with state solar incentives). M. B. Ndaliman, U. Y. Suleiman [17] developed the model equations were used in a case study to investigate the various components of fixed cost, and also to generate the trends of total costs, from which different BEP values were obtained by varying some variables. Results of analysis indicate that BEP has direct relationship with interest rates and inverse relationship with salvage values. Rudolf Kampf, Peter Majercak, Pavel Svagr in their paper aimed to highlight the importance of costs position in the enterprise. If the effort of enterprise is to continuously improve and consolidate its market position, it is necessary to know the exact details of costs area. Knowledge of costs is especially important because the amount of profit usually depends just on the amount of costs. Based on the results are in the paper characterized fixed and variable costs, which depend on changes in production volume and are the basis for determining Break-even point [18]. P. Aswal, M. Kumar, A. Gupta demonstrated In the present study calculation has been done by assigning different parameter to any organization and finding BreakEven analysis by the use of Matlab Programming (simulation) [19]. The approach that the Adriana Mihaela IONESCU, Cristina Elena DUMITRU of this paper have done is theoretical and he recognizes the need for some case studies to understand the complexity of situations that involve the use of break-even analysis, could thus overcome the barrier between the academic discourse and the practice, which would be beneficial to both sides. Other lines of research could be identification of additional effective tools to help professionals in the consolidation of information necessary for making management decisions [20]. Nemanja Stanisic, Goranka Knezevic in their paper use a real life financial data set to examine the applicability of the analysis in both its classical - net and modified - operating forms. The results indicate that the general applicability of break even analysis is rather limited, but also that its "operating" form is noticeably more consistent with the assumptions [21]. The research [22] study aimed to figure out the effect of using break-even point in planning, controlling, and in the decision-making process, in the Jordanian industrial companies. This research study shed the light on the reality of the use of the break-even point in the planning, controlling and decision-making in industrial companies in Jordan. The study sample of the study was formed out of 54 employees in the accounting departments in the Jordanian industrial companies. The study found out that, the most of the Jordanian industrial companies are using break-even point in the planning, controlling and decision-making, and there is a statistical significant relationship between the use of the break-even point and successful planning, control and decision-making in the Jordanian industrial companies. The study has recommended that, companies should use breakeven point as a main tool of decision-making and planning oversight because of its impact, efficiency and accuracy in the rationalization and control decisions. 


\section{APPLICATION, ANALYSIS AND DISCUSSIONS}

Management As mentioned in the above works, management models based on the ratio of costs, production, profit, are sometimes interpreted as the analysis of a critical point or break-even point In the vast majority of break-even analysis is based on the distribution of costs for variables and constants, as well as the calculation of break-even point, which determines the critical volume of sales of manufactured products (services provided). It is known that the break-even point is the amount of activity in which the company's income is equal to its expenses, respectively, the profit is zero. For its calculation, the methods of equation, margin income and graphic interpretation are used.

However, modern variants of resources combinations in carrying out any activity allow us to speak about an analysis not only of the break-even point, but of the whole break-even zone, which with the same volume of production can acquire different values. Exploring the activities of underground storage facilities in Ukraine, we came to the conclusion that for these enterprises there was no single point of break-even, but there was a break-even interval [1,2].

The main factors influencing the basic conditions of the break-even activity of the GHG enterprises are the state of fixed assets (fixed costs), the state of regulatory regulation of tariffs for the injection, collection and storage of natural gas, the decision of NERC (the price of storage of $1000 \mathrm{~m} 3$ of natural gas), the cost resources (variable costs per $1000 \mathrm{~m} 3$ of natural gas. The peculiarity of defining break-even volume for these enterprises is that the price is a complex value that includes the cost of natural gas injection, storage and selection, so the break-even condition is slightly modified.

The break-even point of the enterprise is not constant, it can vary either in the direction of an increase, or towards a decrease, thus forming a zone of impregnability. The most important factor in the formation of a break-even zone for underground storage of gas will be the time: in which business process at the required time is the enterprise - the injection or selection of natural gas. The cost of pumping natural gas into the gas storage and its selection directly depends on the amount of pumped gas, and the cost of storage depends on the volume of natural gas and the duration of storage.

In real enterprise practice, the provisions of the theory of CVP-analysis can be used with significant assumptions and limitations, which sometimes leads to significant errors. Due to the identified by the authors methodological shortcomings $s$ [14], certain categories of fixed costs change either according to certain parameters of the enterprise activity, or accordingly directly to the production and sales volumes, so they will not have a direct mathematical dependence.

In addition, fixed costs remain the same only within a certain volume of production, within the limits of relevance, even if the prices remain unchanged, while the variable costs will also not be constant per unit of production (savings on volumes, "experience curve", discounts on purchasing resources, etc.). Thus, it can be argued that there is no single break-even point for the activity of the enterprise, since there is an entire break-even zone, so we believe that the methodology of break-even zone construction for underground gas storage enterprises will be implemented in the following stages: forming a statistical sample of breakeven zone construction parameters (fixed costs, variable costs, sales revenue); determination of each component average; determining the deviation of average and actual values parameters; definition of mean deviation; formation of the maximum and minimum value of each of the formula parameters for determining the break-even point; construction of the minimum and maximum break-even point; the space between such points will be recognized as a break-even zone.

Based on the statistics of an individual enterprise for underground storage of natural gas, the authors [2] calculated its average value and determined the deviation of the actual values from the average, which is reflected in table 1.

TABLE I. Deviations And Variability Of Deviations Percent [2]

\begin{tabular}{|l|l|l|l|l|l|}
\hline \multicolumn{2}{|c|}{$\begin{array}{c}\text { Percentage of deviations from } \\
\text { the average, \% }\end{array}$} & \multicolumn{3}{c|}{ Variability, \% } \\
\hline $\begin{array}{c}\text { Constant } \\
\text { costs, } \\
\text { ths. } \\
\text { UAH }\end{array}$ & $\begin{array}{c}\text { Variable } \\
\text { costs, } \\
\text { ths. } \\
\text { UAH }\end{array}$ & $\begin{array}{c}\text { Revenue } \\
\text { from } \\
\text { sales, } \\
\text { ths. UAH }\end{array}$ & $\begin{array}{c}\text { Constant } \\
\text { costs, } \\
\text { ths. } \\
\text { UAH }\end{array}$ & $\begin{array}{c}\text { Variable } \\
\text { costs, } \\
\text { ths. } \\
\text { UAH }\end{array}$ & $\begin{array}{c}\text { Revenue } \\
\text { from } \\
\text { sales, } \\
\text { ths. } \\
\text { UAH }\end{array}$ \\
\hline 3.4 & 2.5 & 0.1 & 3.4 & 2.5 & 0.1 \\
\hline 1.1 & 2.3 & 1.8 & 1.1 & 2.3 & 1.8 \\
\hline 1.1 & -4.1 & -1.1 & 1.1 & 4,1 & 1.1 \\
\hline-10.2 & -0.9 & 5.6 & 10.2 & 0.9 & 5.6 \\
\hline-6.6 & -0.6 & -2.2 & 6.6 & 0.6 & 2.2 \\
\hline-1.4 & -1.6 & 0.9 & 1.4 & 1.6 & 0.9 \\
\hline 4.9 & 0.1 & -0.9 & 4.9 & 0.1 & 0.9 \\
\hline 4.7 & -0.6 & -3.0 & 4.7 & 0.6 & 3.0 \\
\hline 3.0 & 1.6 & 0.9 & 3.0 & 1.6 & 0.9 \\
\hline-1.9 & 0.0 & -2.9 & 1.9 & 0.0 & 2.9 \\
\hline 0.1 & 5.3 & 0.3 & 0.1 & 5.3 & 0.3 \\
\hline 1.7 & -4.1 & 0.5 & 1.7 & 4.1 & 0.5 \\
\hline Average value & & 3.3 & 2.0 & 1.7 \\
\hline
\end{tabular}

On the basis of the scale of the deviations percentage, the minimum and maximum values of the break-even conditions parameters are determined. The minimum and maximum price are $278 \mathrm{UAH}$ and $297 \mathrm{UAH}$, the minimum and maximum variable cost $1000 \mathrm{~m} 3$ are $222 \mathrm{UAH} / 1000 \mathrm{~m} 3$ and $230 \mathrm{UAH} / 1000 \mathrm{~m} 3$, the minimum and maximum constant are $65616 \mathrm{UAH}$ and $67834 \mathrm{UAH}$.

Based on the formed parameters of the break-even condition, we constructed a minimum and maximum breakeven point, and the zone in the range A-B-C-D (see Fig. 2) is the break-even zone.

Consequently, highlighted by the dotted line break-even zone, is limited by the lines: the minimum income; maximum income; minimum total cost; maximum total cost.

Finding the area of this figure and its relationship with the financial security zone (profitability) and the zone of losses will determine the level of break-even activity of the investigated enterprise. 


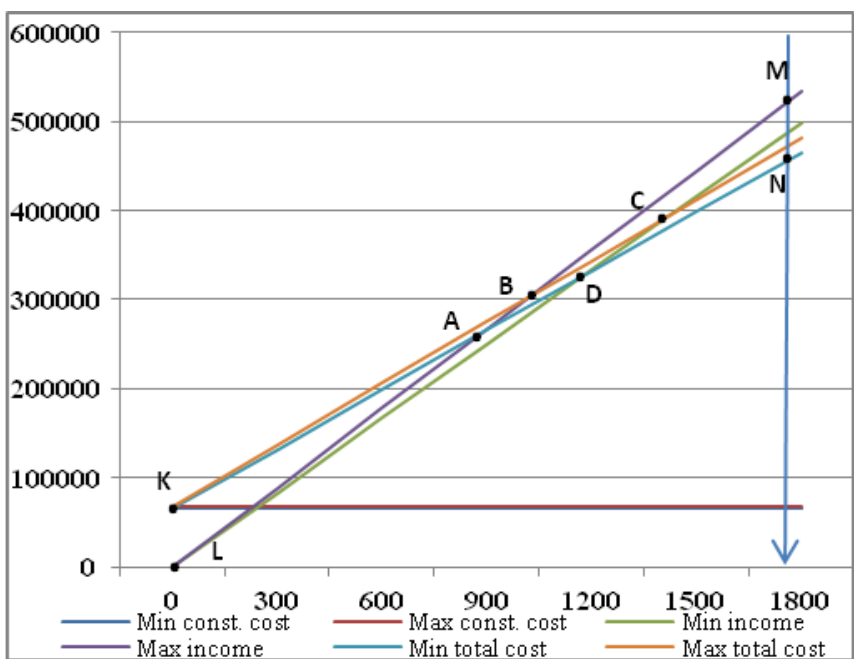

Fig. 1. The zone of break-even activity of the natural gas underground storage enterprise.

Thus, in constructing a break-even zone, we received three figures: ABCD - break-even zone; LKBAD - loss zone; BCDNM - a zone of financial security, where restrictions (line $\mathrm{MN}$ ) will be the actual volume of pumped and selected natural gas; BCDNM - profitability zone where the limit (MN line) for natural gas underground storage companies will be the maximum active volume of natural gas storage.

From the obtained calculations and results of economic and mathematical modeling of the break-even zone, it is determined that the break-even volume of pumped and selected natural gas will fluctuate between 1010.53 million $\mathrm{m} 3$ of natural gas and 1139.82 million $\mathrm{m} 3$. These values are integral bounds for the area of the break-even zone (Table 2).

TABLE II. RESTRICTED LINES OF EXISTING AREAS OF ThE ENTERPRISE ACTIVITY

\begin{tabular}{|l|l|}
\hline \multicolumn{1}{|c|}{$\begin{array}{c}\text { Type of activity } \\
\text { area }\end{array}$} & \multicolumn{1}{c|}{ Limit lines } \\
\hline Zone of losses & $\begin{array}{l}\text { line of minimum income: } y=278 * x \\
\text { line of minimum total costs: } y=65616+222 * x \\
\text { line of maximum income: } y=297 * x \\
\text { line of maximum total costs: } y=67834+230 * x\end{array}$ \\
\hline Break-even zone & $\begin{array}{l}\text { line of minimum total costs: } y=65616+222 * x \\
\text { line of maximum income: } y=297 * x \\
\text { line of minimum income: } y=278 * x\end{array}$ \\
\hline $\begin{array}{l}\text { Financial } \\
\text { zone }\end{array}$ & $\begin{array}{l}\text { line of maximum income: } y=297 * x \\
\text { line of maximum total costs: } y=67834+230 * x \\
\text { line of minimum income: } y=278 * x \\
\text { line of minimum total costs } y=65616+222 * x\end{array}$ \\
\hline
\end{tabular}

Therefore, in order to determine the break-even level of underground gas storage enterprises, it is important to calculate areas of loss, break-even, financial security and profitability and to correlate them with each other.Table 2 shows the bounding lines for each of the identified zones.

The next step is to determine the integration boundaries for each of these zones. To do this, we have defined the points of intersection of the lines, namely: line of maximum income and minimum total expenses; line of maximum income and maximum total costs; line of maximum total costs and minimum income; line of minimum income and minimum total costs.

By determining the coordinates of each of the intersection points, received accordingly: point A (874; 259578); point B (1012; 300564); point C (1413; 392814); point D $(1171 ; 325538)$ (Table 3$)$.

TABLE III. DETERMINATION OF THE AREAS OF THE EACH TYPE OF ENTERPRISE ACTIVITY

\begin{tabular}{|c|c|c|}
\hline Algorithm for calculating the area & $\begin{array}{l}\text { Area, } \\
\text { mln. }\end{array}$ & $\begin{array}{l}\text { Share } \\
\text { in the } \\
\text { area } \\
\text { of } \\
\text { gener } \\
\text { al } \\
\text { activit } \\
\text { y, \% }\end{array}$ \\
\hline \multicolumn{3}{|l|}{ Zone of losses } \\
\hline $\begin{array}{l}\int_{0}^{874}(65616+222 x) d x-\int_{0}^{874} 278 x d x=35959856 \\
\int_{0}^{1012}(67834+230 x) d x-\int_{0}^{1012} 297 x d x=72988982\end{array}$ & 108.94 & 62.2 \\
\hline \multicolumn{3}{|l|}{ Zone of break-even } \\
\hline $\begin{array}{l}\int_{874}^{1012}(297 x) d x-\int_{874}^{1012}(65616+222 x) x d x=705042 \\
\int_{1012}^{1171}(67834+230 x) d x-\int_{1012}^{1171}(65616+222 x) x d x=1741050 \\
\int_{1171}^{1413}(67834+230 x) d x-\int_{1171}^{1413}(278 x) x d x=1407956\end{array}$ & 3.854 & 2.2 \\
\hline \multicolumn{3}{|l|}{ Zone of financial security } \\
\hline $\begin{array}{l}\int_{1012}^{1413}(297 x) d x-\int_{1012}^{1413}(67834+230 x) x d x=5374800 \\
\int_{1171}^{1413}(278 x) d x-\int_{1171}^{1413}(65616+222 x) x d x=1630112 \\
\int_{1413}^{1640}(297 x) d x-\int_{1413}^{1640}(65616+222 x) x d x=1103800\end{array}$ & 8.108 & 4.6 \\
\hline \multicolumn{3}{|l|}{ Zone of potential profitability } \\
\hline $\int_{1640}^{2300}(297 x) d x-\int_{1640}^{2300}(65616+222 x) x d x=54208440$ & 54.208 & 31.0 \\
\hline
\end{tabular}

As a result of building a zone of loss-making, break-even and profits, we received a curvilinear flat shape, which is limited by lines: $y=f(x) \geq 0 ; \quad y=0 ; \quad x=a$. Where $a$ - the maximum active volume of natural gas underground storage which, as a chosen criterion, transforms the solution of the problem from the definition of an indefinite integral to a definied integral. So, to calculate the area of the curvilinear figure is divided $[0 ; a]$ on $\mathrm{n}$ segments with points of intersection $x_{i}, i=(0 ; n)$, so that $x_{0}=0<x_{1}<x_{2}<\ldots<x_{\mathrm{n}}=a$. So in our case the line of constraints will be $x_{0}=0 ; x_{1}=874 x_{2}=1012$ $x_{3}=1171, x_{4}=1413, x_{5}=2164$. 
Consequently, using the properties of a definite integral the areas of each of the activity zones are calculated. Taking into account the properties of certain integrals and the given conditions of an enterprise's activity, it is possible to determine the areas of the given figures, which are defined areas of activity (Table 3 ).

In assessing the level of break-even activity, it is necessary to compare the break-even zone with the zone of loss-making, financial security and potential profitability, assuming that all activities of the enterprise takes the value equal to $100 \%$ and occupies the entire area.

\section{CONCLUSIONS \& RECOMMENDATIONS}

Therefore, according to the results of economic and mathematical modeling of the underground storage of natural gas enterprise break-even zone activity, it should be emphasized that the largest share in the zone of the total probable activity of the enterprise is occupied by the loss zone and makes $62.2 \%$, the break-even zone accounts for $2.2 \%$, and financial enterprise security occupies only $4.6 \%$ of the total area of the enterprise activity, and a significant share in the activity of the underground storage of natural gas enterprise falls in the area of potential profit, which is approx. $31 \%$

Such results indicate the need to optimize the activity of the enterprise by reducing the area of losses and increasing the use of the area of potential profit, by using unused reserves. However, a very low level of financial security should be emphasized, indicating a significant underutilization of UGS production capacity, primarily due to the underutilisation of the GTS of Ukraine. Therefore, the proposed methodology and its adaptation to the conditions of real UGS proves that gas transportation system enterprises should apply exchange mechanisms to the utilization of production facilities through the creation of a gas hub, gas warehouses, open bidding and a transparent natural gas market, which will allow to form a market price for pumping, storage and extraction of natural gas and thus increase the profitability area. The recommendations of the European Commission and the European Parliament, which wish to achieve the objectives of the EU 2020 Strategy through a secure, competitive, reliable energy supply to the economy and society, should also be heeded. The European Union recommends three possible policies to mitigate the market impact of the largest energy generating companies: property banding, independent system operator and independent network operator [8].

\section{REFERENCES}

[1] L. T. Horal, and O. L. Jaroshenko, "A vision of underground storage of natural gas in sustainable development", Economic forum, vol. 4 pp. 4-12, 2017

[2] O. Yaroshenko, "Methodological-applied bases determination of the break-even activities enterprises of gas storages", Intellect XXI, vol 4, pp.126-130, 2017.

[3] Y. V. Masuk, and V.V. Ivanchenko, "Theoretical basis of the calculation of break-even point", Young Scientist, vol. 1 (41), pp. 654 657, January, 2017
[4] S. D. Skurtol, "Modelling of break-even point of production using information technologies", Problems and prospects of economic and management, vol. 2(2), pp. 70-75, 2016.

[5] M. V. Babenko, and M. Yu. Bratuta, "Using methods to determine the value of software development in the analysis of break-even creation of information systems", Collection of scholarly papers of Dniprovsk State Technical University (Technical Sciences, vol. 1, pp. 123-127, 2016.

[6] O. G. Iankovyi, and V. O. Iankovyi, "Manage profitability at the enterprise level using cvp analysis", Foreign trade: economics, finance, law, vol. 1, pp. 17-30, 2015.

[7] N. L. Yushchenko, and Y. P. Kuslyi, "Models and software solutions for break-even activity", Scientific bulletin of Polissia, vol. 4(4), pp. 76-86, 2015

[8] N. Vecepura, "Using the analysis of break-even in conditions of enterprises of socio-cultural sphere", Economy and management of culture, vol 1, pp. 66-75, 2015

[9] S. Tkachenko, "Strategies to ensure break-even and economic sustainability of agricultural enterprises", Investytsiyi: praktyka ta dosvid, vol. 3, pp. 71-75, 2015.

[10] O. M Tarasenko, and O. O. Gusha, "Break-even point of bus transportation", The National Transport University Bulletin: A Scientific and Technical Journal, vol. 31, pp. 508-512, 2015.

[11] O. M. Tarasenko, and O. O. Gusha, "The scope of bus transportations", The National Transport University Bulletin: A Scientific and Technical Journal, vol. 21(2), pp. 232-234, 2010.

[12] M. O. Pryliepova, Ye. R. Tian, and A. M. Yakymenko, "Methodological recommendations for managing the "break-even zone" of the enterprise", Build production, vol. 58, pp. 21-28, 2015.

[13] N. L. Yushchenko, and Y. P. Kuslyi, "Models and software solutions for break-even activity", Scientific bulletin of Polissia, vol. 4(4), pp. 76-86, 2015.

[14] S. I. Chymshyt, and I. S. Hrabovs'kyj, "Methodological aspects of evaluation and areas break-even analysis\|”, Halyts'kyj ekonomichnyj visnyk, vol. 46, pp. 155-170, 2014.

[15] Dr. Murari Premnath Sharma, "Study of Banking Break Even Point: An Innovative Tool for Banking Industry", International Jornal of Innovative research \& development, vol 3 Issue 11 pp. 164-168, 2014

[16] Minhyun LEE, Taehoon HONG, Choongwan KOO, and Chan-Joong KIM, "A break-even analysis and impact analysis of residential solar photovoltaic systems considering state solar incentives", Technological and Economic Development of Economy, vol. 24(2) pp. 358-382, 2018.

[17] M. B. Ndaliman, and U. Y. Suleiman, "An Economic Model for Break-even Analysis", Conference: 2nd International Conference on Mechanical and Manufacturing Engineering (ICME 2011)., At PICC, Putrajaya, Malaysia June 2011.

[18] Rudolf Kampf, Peter Majerčak, and Pavel Švagr, "Application of Break-Even Point Analysis Primjena Break-Even Point analize", Naše more, vol. 63(3), pp. 126-128, 2016

[19] P. Aswal, M. Kumar, and A. Gupta, "A Study on the Organizational Output by Concluding Break Even -Point through the Application of Matlab Simulink Method" Int. J. Manag. Bus. Res., vol. 4 (1), pp. 35 41, 2014.

[20] Adriana Mihaela Ionescu, and Cristina Elena Dumitru, "Break-even in the decision making process", Challenges of the Knowledge Society, vol. 5, pp. 778-783(6), 2015.

[21] Nemanja Stanisic, and Goranka Knezevic "Break-even: Just another academic amusement or useful additi financial practitioners' toolbox", Conference: FINIZ Singidunum University International Scientific Conferenc, pp. 45-47, 2014.

[22] Dr. Nabil Alnasser, Dr. Osama Samih Shaban, and Dr. Ziad Al-Zubi, "The Effect of Using Break-Even-Point in Planning, Controlling, and Decision Making in the Industrial Jordanian Companies", International Journal of Academic Research in Business and Social Sciences, vol. 4, no. 5, May 2014. 